\title{
Electrophoretic Deposition of Salinized Organic Molecules Inducing Desirable Intermolecular Packing Style for Improving Sandwiched Device Electrical Performance
}

Yanna Su, Cheng Zhang, Qijian Zhang, Jianrong Zeng, Hua Li*, Jianmei Lu*

Materials

4-Pyridineboronic acid, 9-phenyl-9H-carbazole, N-bromosuccinimide, butan-1-amine and bis(pinacolato)diboron were purchased from commercial sources (i.e., TCI, Sigma-Aldrich Co. Ltd). These chemicals were used without further purification. All solvents were purchased solvents from Energy Chemical.

Synthesis procedure

6-Bromo-2-butyl-1H-benzo[de]isoquinoline-1,3(2H)-dione(5):

6-Bromo-1H,3H-benzo[de]isochromene-1,3-dione $(5.0 \mathrm{~g}, 18 \mathrm{mmol})$ and $100 \mathrm{~mL}$ ethanol was added to a $250 \mathrm{~mL}$ three-necked flask, followed by adding n-butylamine (2.64 g, $36 \mathrm{mmol}$ ) during stirring. The mixture was refluxed at $85^{\circ} \mathrm{C}$ for $16 \mathrm{~h}$. After the reaction was completed, the mixture was filtered and washed with cold ethanol to obtain the final product ( $4.5 \mathrm{~g}$, yield: $75 \%$ ).

2-Butyl-6-(4,4,5,5-tetramethyl-1,3,2-dioxaborolan-2-yl)-1H-benzo[de]isoquinoline-1,3 (2H)-dione (6): Product 5 (3.98 g, $12 \mathrm{mmol})$, pinacol borate (6.10 g, $24 \mathrm{mmol})$, 
potassium acetate $(5.88 \mathrm{~g}, 60 \mathrm{mmol})$ and $150 \mathrm{~mL}$ toluene were added to a $250 \mathrm{~mL}$ reaction vial, then the catalyst $\mathrm{Pd}(\mathrm{dppf}) \mathrm{Cl}_{2}(438.6 \mathrm{mg}, 0.6 \mathrm{mmol})$ was added under $\mathrm{N}_{2}$ atmosphere. The mixture was refluxed at $70{ }^{\circ} \mathrm{C}$ for $12 \mathrm{~h}$. After completion of the reaction, the solvent was evaporated to dryness, the product was extracted with ethyl acetate for three times and purifyed by the silica gel column chromatography (n-hexane/dichloromethane $=1: 2)$ to give a product $2-1(3.8 \mathrm{~g}$, yield: $83.7 \%) .{ }^{1} \mathrm{H}$ NMR $\left(400 \mathrm{MHz}, \mathrm{CDCl}_{3}\right) \delta 9.11(\mathrm{~d}, J=0.8,1.1 \mathrm{~Hz}, 1 \mathrm{H}), 8.60(\mathrm{dd}, J=7.3,1.1 \mathrm{~Hz}$, 2H), $8.56(\mathrm{~d}, J=7.3 \mathrm{~Hz}, 1 \mathrm{H}), 8.29(\mathrm{~d}, J=7.3 \mathrm{~Hz}, 1 \mathrm{H}), 7.77(\mathrm{dd}, J=7.2,7.3 \mathrm{~Hz}, 1 \mathrm{H})$, $4.21-4.16(\mathrm{~m}, 2 \mathrm{H}), 1.73(\mathrm{~s}, 2 \mathrm{H}), 1.49-1.44(\mathrm{~m}, 14 \mathrm{H}), 0.98(\mathrm{t}, J=7.4 \mathrm{~Hz}, 3 \mathrm{H})$.

3-Bromo-9-phenyl-9H-carbazole (2): 9-phenyl-9H-carbazole (2.0 g, $8.2 \mathrm{mmol})$ was dissolved in $20 \mathrm{~mL}$ of DMF by stirring in an ice water bath, followed by slowly-added NBS $(1.76 \mathrm{~g}, 9.86 \mathrm{mmol})$ in the dark. The mixture reacted at $0{ }^{\circ} \mathrm{C}$ for $1 \mathrm{~h}$ and then refluxed $80^{\circ} \mathrm{C}$ overnight. After completion of the reaction, the mixture was extracted with $\mathrm{CH}_{2} \mathrm{Cl}_{2}$ and concentrated under reduced pressure. The crude product was purified by the silica gel column chromatography (n-hexane/dichloromethane $=1: 2$ ) to obtain a compound 1 (3.3 g, yield: $79 \%) .{ }^{1} \mathrm{H}$ NMR $\left(400 \mathrm{MHz}, \mathrm{CDCl}_{3}\right) \delta 8.25(\mathrm{~s}$, 1H), $8.09(\mathrm{~d}, J=7.7 \mathrm{~Hz}, 1 \mathrm{H}), 7.61(\mathrm{t}, J=7.7 \mathrm{~Hz}, 1 \mathrm{H}), 7.53(\mathrm{~d}, J=7.7 \mathrm{~Hz}, 2 \mathrm{H}), 7.48$ $(\mathrm{d}, J=7.7 \mathrm{~Hz}, 2 \mathrm{H}), 7.41(\mathrm{dd}, J=7.2,7.5 \mathrm{~Hz}, 2 \mathrm{H}), 7.33-7.27(\mathrm{~m}, 2 \mathrm{H})$.

3-Bromo-9-phenyl-6-(pyridin-4-yl)-9H-carbazole (3): Product 2 (5.0 g, 15 mmol), pyridine-4-boronic acid (3.81 g, $30 \mathrm{mmol})$ and $\mathrm{K}_{2} \mathrm{CO}_{3}(6.21 \mathrm{~g}, 45 \mathrm{mmol})$ were added into a $500 \mathrm{~mL}$ three-neck round bottom flask with mixed solvent of 1,4- Dioxane (150 $\mathrm{mL})$ and $\mathrm{H}_{2} \mathrm{O} \quad(30 \mathrm{~mL})$, followed by adding the catalyst of 
tetrakistriphenylphosphine palladium under $\mathrm{N}_{2}$ atmosphere. The mixture was refluxed at $80{ }^{\circ} \mathrm{C}$ for $12 \mathrm{~h}$. After completion of the reaction, the mixture was extracted with ethyl acetate for three times, and purified by silica gel column chromatography (PE / $\mathrm{EA}=3: 1)$ to give the pure compound, which was dissolved in $20 \mathrm{~mL}$ of DMF by stirring in an ice water bath, followed by slowly-added NBS in the dark. The mixture reacted at $0{ }^{\circ} \mathrm{C}$ for $1 \mathrm{~h}$ and then refluxed $80{ }^{\circ} \mathrm{C}$ overnight. After completion of the reaction, the mixture was extracted with $\mathrm{CH}_{2} \mathrm{Cl}_{2}$ and concentrated under reduced pressure. The crude product was purified by the silica gel column chromatography (n-hexane/dichloromethane $=1: 2$ ) to obtain a compound 3 , and the obtained crude compound was directly subjected to the next reaction.

\section{2-Butyl-6-(9-phenyl-6-(pyridin-4-yl)-9H-carbazol-3-yl)-1H-benzo[de]isoquinoline-1,3}

(2H)-dione (CzPy): Crude product 3 (1.0 g, $2.5 \mathrm{mmol})$, compound 2-1 (1.89 g, 5.0 mmol) were dissolved in a mixed solvent of toluene $(100 \mathrm{~mL})$ and water $(12 \mathrm{~mL})$, followed by the addition of $\mathrm{CsCO}_{3}(2.4 \mathrm{~g}, 12.5 \mathrm{mmol})$. The catalyst tetrakistriphenylphosphine palladium was added under $\mathrm{N}_{2}$ atmosphere. Then the mixture was refluxed at $100{ }^{\circ} \mathrm{C}$ for $12 \mathrm{~h}$. After completion of the reaction, the mixture was extracted with $\mathrm{CH}_{2} \mathrm{Cl}_{2}$, and purified by silica gel column chromatography to give the compound $4(1.11 \mathrm{~g}$, yield $77.6 \%) .{ }^{1} \mathrm{H}$ NMR $\left(400 \mathrm{MHz}, \mathrm{CDCl}_{3}\right) \delta 8.70(\mathrm{~d}, \mathrm{~J}=7.5$ $\mathrm{Hz}, 1 \mathrm{H}), 8.68(\mathrm{~d}, \mathrm{~J}=1.5 \mathrm{~Hz}, 1 \mathrm{H}), 8.66(\mathrm{dd}, \mathrm{J}=5.8,1.4 \mathrm{~Hz}, 2 \mathrm{H}), 8.48(\mathrm{~d}, \mathrm{~J}=1.5 \mathrm{~Hz}$, 1H), $8.40(\mathrm{dd}, \mathrm{J}=0.8,1.1 \mathrm{~Hz}, 1 \mathrm{H}), 8.36(\mathrm{~s}, 1 \mathrm{H}), 7.84(\mathrm{~d}, \mathrm{~J}=7.5 \mathrm{~Hz}, 1 \mathrm{H}), 7.78$ (dd, J $=1.6,1.8 \mathrm{~Hz}, 1 \mathrm{H}), 7.74-7.71(\mathrm{~m}, 1 \mathrm{H}), 7.70(\mathrm{~d}, \mathrm{~J}=1.3 \mathrm{~Hz}, 1 \mathrm{H}), 7.69-7.64(\mathrm{~m}, 5 \mathrm{H})$, $7.59(\mathrm{t}, \mathrm{J}=2.1 \mathrm{~Hz}, 2 \mathrm{H}), 7.58-7.54(\mathrm{~m}, 2 \mathrm{H}), 4.27-4.22(\mathrm{~m}, 2 \mathrm{H}), 1.80-1.75(\mathrm{~m}$, 
2H), $1.49(\mathrm{dd}, \mathrm{J}=7.6,7.5 \mathrm{~Hz}, 2 \mathrm{H}), 1.01(\mathrm{t}, \mathrm{J}=7.4 \mathrm{~Hz}, 3 \mathrm{H}) .{ }^{13} \mathrm{C}$ NMR $(400 \mathrm{MHz}$, Chloroform-d) $\delta 164.41,164.23,150.26,148.77,147.45,141.93,141.40,137.05$, $132.91,131.13,130.84,130.52,130.46,130.23,128.84,128.52,128.27,128.21$, $127.09,126.80,125.62,123.81,123.58,122.99,121.96,121.64,121.48,119.12$, 110.80, 110.32, 40.31, 30.28, 20.4 , 13.91 . Elemental analysis (\%) calcd for CzPy: C, $80.70 ; \mathrm{H}, 4.84 ; \mathrm{N}, 6.99$.

4-(6-(2-Butyl-1,3-dioxo-2,3-dihydro-1H-benzo[de]isoquinolin-6-yl)-9-phenyl-9H-ca rbazol-3-yl)-1-hexylpyridin-1-ium (CzPyN) : The product 4 (300 mg, $0.52 \mathrm{mmol})$ was dissolved in DMF, then bromohexane (852 $\mathrm{mg}, 5.2 \mathrm{mmol}$ ) was slowly added into the system. The mixture refluxed at $90{ }^{\circ} \mathrm{C}$ for $24 \mathrm{~h}$. After completion of the reaction, 150 $\mathrm{mL}$ water was added to precipitate the product, and which was filtered out to give a yellow compound 5 (313 mg, yield: 91\%). ${ }^{1} \mathrm{NMR}(400 \mathrm{MHz}$,$) ) 9.35(\mathrm{~s}, 2 \mathrm{H}), 9.08(\mathrm{~d}$, $\mathrm{J}=5.1 \mathrm{~Hz}, 1 \mathrm{H}), 8.81(\mathrm{~s}, 1 \mathrm{H}), 8.54(\mathrm{~d}, \mathrm{~J}=3.9 \mathrm{~Hz}, 0 \mathrm{H}), 8.51(\mathrm{~d}, \mathrm{~J}=6.6 \mathrm{~Hz}, 1 \mathrm{H}), 8.46$ $(\mathrm{d}, \mathrm{J}=5.0 \mathrm{~Hz}, 1 \mathrm{H}), 8.33(\mathrm{~d}, \mathrm{~J}=8.2 \mathrm{~Hz}, 1 \mathrm{H}), 7.95(\mathrm{~d}, \mathrm{~J}=8.2 \mathrm{~Hz}, 1 \mathrm{H}), 7.74(\mathrm{~d}, \mathrm{~J}=7.5$ $\mathrm{Hz}, 1 \mathrm{H}), 7.69(\mathrm{~s}, 1 \mathrm{H}), 7.67(\mathrm{~d}, \mathrm{~J}=2.5 \mathrm{~Hz}, 1 \mathrm{H}), 7.61-7.58(\mathrm{~m}, 2 \mathrm{H}), 7.54-7.51(\mathrm{~m}$, $1 \mathrm{H}), 4.81(\mathrm{t}, \mathrm{J}=7.1 \mathrm{~Hz}, 2 \mathrm{H}), 4.21-4.16(\mathrm{~m}, 2 \mathrm{H}), 2.07-2.00(\mathrm{~m}, 2 \mathrm{H}), 1.74(\mathrm{dd}, \mathrm{J}=$ 2.0, $3.9 \mathrm{~Hz}, 6 \mathrm{H}), 1.51-1.42(\mathrm{~m}, 4 \mathrm{H}), 0.99(\mathrm{t}, \mathrm{J}=7.3 \mathrm{~Hz}, 3 \mathrm{H}), 0.87(\mathrm{t}, \mathrm{J}=7.0 \mathrm{~Hz}$, $3 \mathrm{H}) .{ }^{13} \mathrm{C}$ NMR (400 MHz, Chloroform-d) $\delta 164.15,163.89,156.15,146.78,144.01$, $143.40,136.20,132.73,131.68,130.70,130.41,130.28,129.84,129.10,128.55$, $128.07,126.82,126.74,125.91,124.76,124.25,124.10,123.2,122.98,122.52$, $121.82,111.12,110.37,77.28,60.83,40.24,35.59,34.72,31.63,31.15,30.21$, 
25.81, 22.38, 20.43, 13.93 , 13.89. Elemental analysis (\%) calcd for $\mathbf{C z P y N}$ : C, 81.91; H, 5.09; N, 5.37.

\section{Optimization of the EPD process}

\section{Solvent}

The polar or non-polar organic solvents are the favorable liquid medium for the EPD process, where the water is not suggested to be used because of the possible electrolysis reaction to cause the escape of hydrogen and oxygen on the electrode, leading to a low-quality deposited thin-film. In consideration of the poor solubility of salinized organic molecules in non-polar solvents (Figure S9), here, polar solvents are selected as the electrolyte solution. By comparing the film deposited from two different polar solvents (acetonitrile and dichloromethane), it is found that the organic film obtained from the acetonitrile solution turned out to be more uniform and dense (Figure S10). Therefore, anhydrous acetonitrile has been chosen as a suitable solvent for the preparation of high-quality EPD films.

\section{Electrolyte concentration}

To study the optimal electrolyte concentration, a series of different concentrations of electrolyte solutions varying from 0.1 to $0.5 \mathrm{mg} \cdot \mathrm{mL}^{-1}$ have been prepared for comparative depositions under the same applied voltage and deposition time. As shown in Figure S11, the AFM image of the film generated from the low concentration $\left(0.1 \mathrm{mg} \cdot \mathrm{mL}^{-1}\right)$ showed a continuous sheet-like surface structure. At a moderate concentration of $0.2 \mathrm{mg} \cdot \mathrm{mL}^{-1}$, the as-obtained film surface presents a uniform accumulation of nanoparticles. When the deposition performs at a higher concentration, some large pores appear on the corresponding film surface with 
increased surface roughness. Therefore, we pick the concentration of $0.2 \mathrm{mg} \cdot \mathrm{mL}^{-1}$ and acetonitrile electrolytes as the preferred conditions for the EPD process.

\section{Applied voltage and deposition time}

To further investigate the influence of electric field intensity and deposition time on the morphology and thickness of the deposited film, we prepare a series of different EPD films under various voltage and deposition time. Some representative AFM surface morphologies of films are shown in Figure S12. The films deposited under different applied voltages reveal a similar morphology at the same deposition time (3 minutes), indicating that the voltage has a limited effect on the roughness and compactness of the film. A representative film that is fabricated at the voltage of $8 \mathrm{~V}$, shows a uniform roughness $(\mathrm{Ra}=2.39 \mathrm{~nm})$ and a dense surface which is fabricated at the voltage of $8 \mathrm{~V}$. As the UV-Vis spectroscopy is shown in Figure S13, when the voltage and electrolyte concentration keep constant, the thickness of the EPD film increases with the prolonged deposition time (Figure S14).

\section{Characterization}

All NMR spectra were obtained using an Inova $400 \mathrm{MHz}$ FT-NMR workstation. Thermogravimetric analysis (TGA) of the compounds was measured on a Perkin-Elmer Diamond TG DTA instrument at the heating rate of $10{ }^{\circ} \mathrm{C} \mathrm{min}^{-1}$ and an $\mathrm{N}_{2}$ flow rate of $50 \mathrm{~mL} \mathrm{~min}^{-1}$. The UV-Visible absorption spectrum was measured by using a UV-3600 spectrophotometer (Shimadzu). The surface topography of the atomic force microscope was scanned using an MF P-3DTM (Digital Instruments / Asylum Research) AFM instrument. XRD was measured using a polycrystalline X-ray diffractometer (X'Pert PRO, PANalytical). The device was tested and 
characterized using a Keithley 4200-SCS semiconductor tester.

\section{Figures}

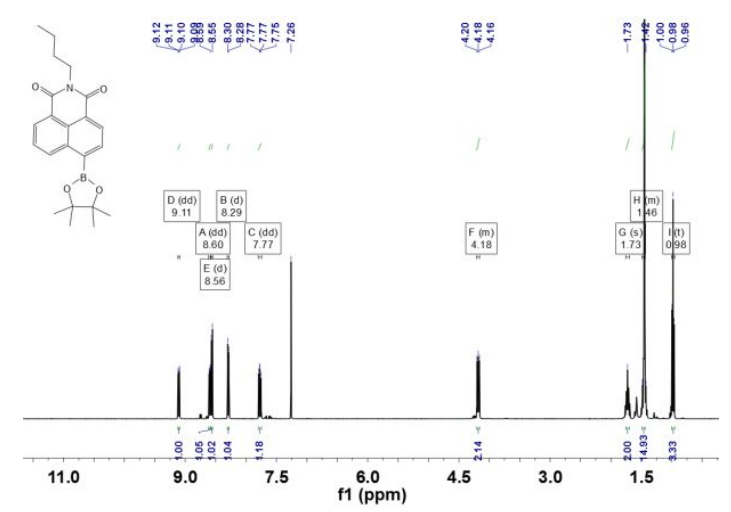

Figure S1. The ${ }^{1} \mathrm{H}$ NMR spectrum of compound 6 in $\mathrm{CDCl}_{3}$.

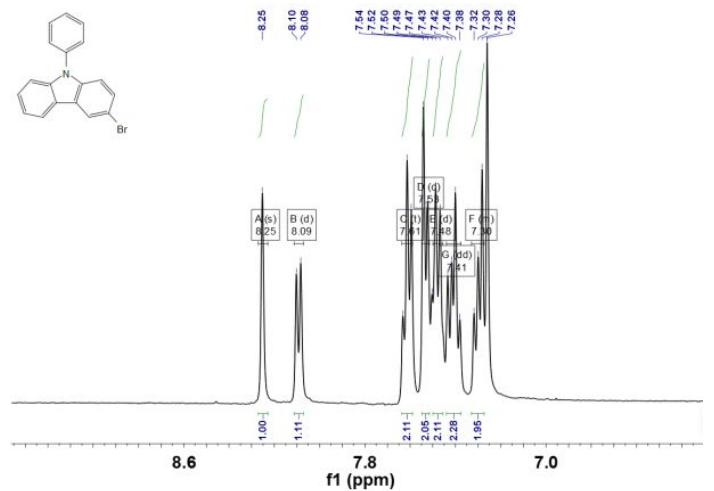

Figure S2. The ${ }^{1} \mathrm{H}$ NMR spectrum of compound 2 in $\mathrm{CDCl}_{3}$.

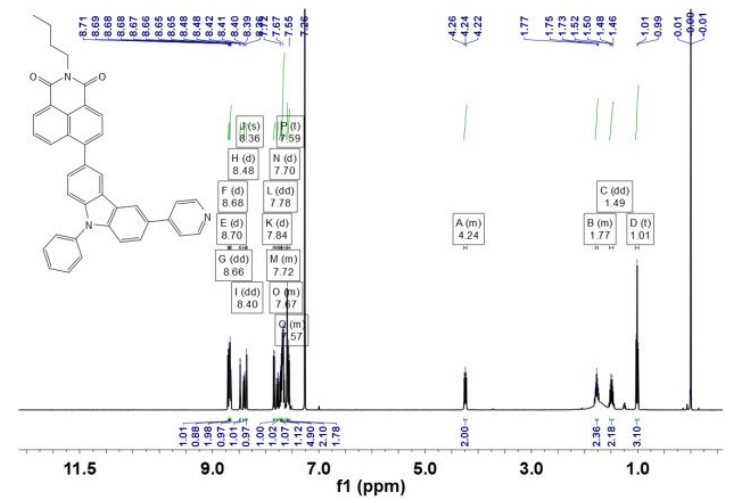

Figure S3. The ${ }^{1} \mathrm{H}$ NMR spectrum of compound $\mathbf{C z P y}$ in $\mathrm{CDCl}_{3}$. 


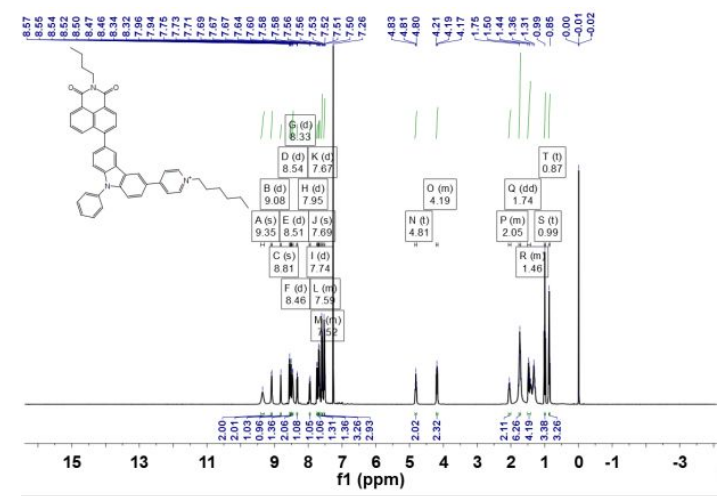

Figure S4. The ${ }^{1} \mathrm{H}$ NMR spectrum of compound $\mathbf{C z P y N}$ in $\mathrm{CDCl}_{3}$.

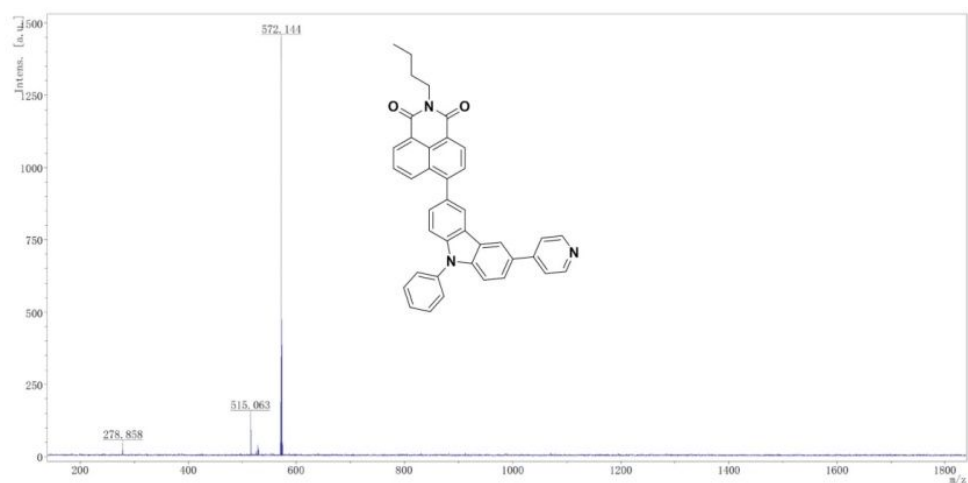

Figure S5. MALDI-TOF MS spectrum of molecule CzPy.

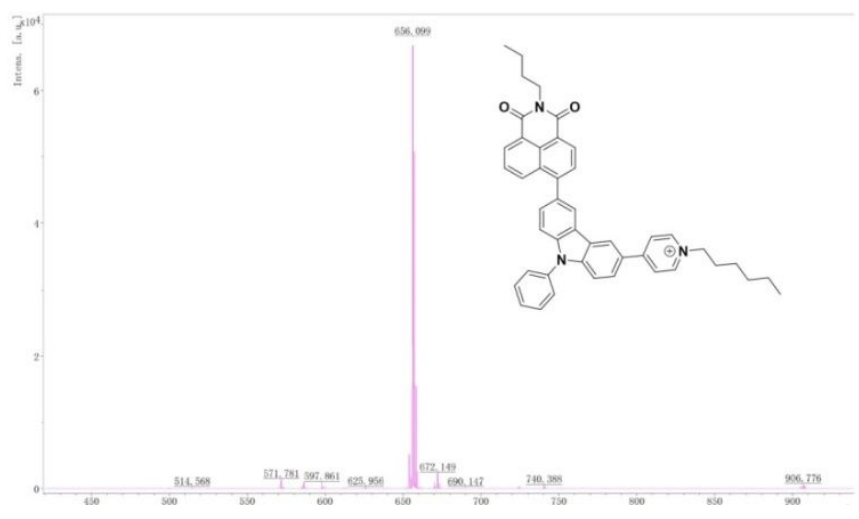

Figure S6. MALDI-TOF MS spectrum of molecule CzPyN. 


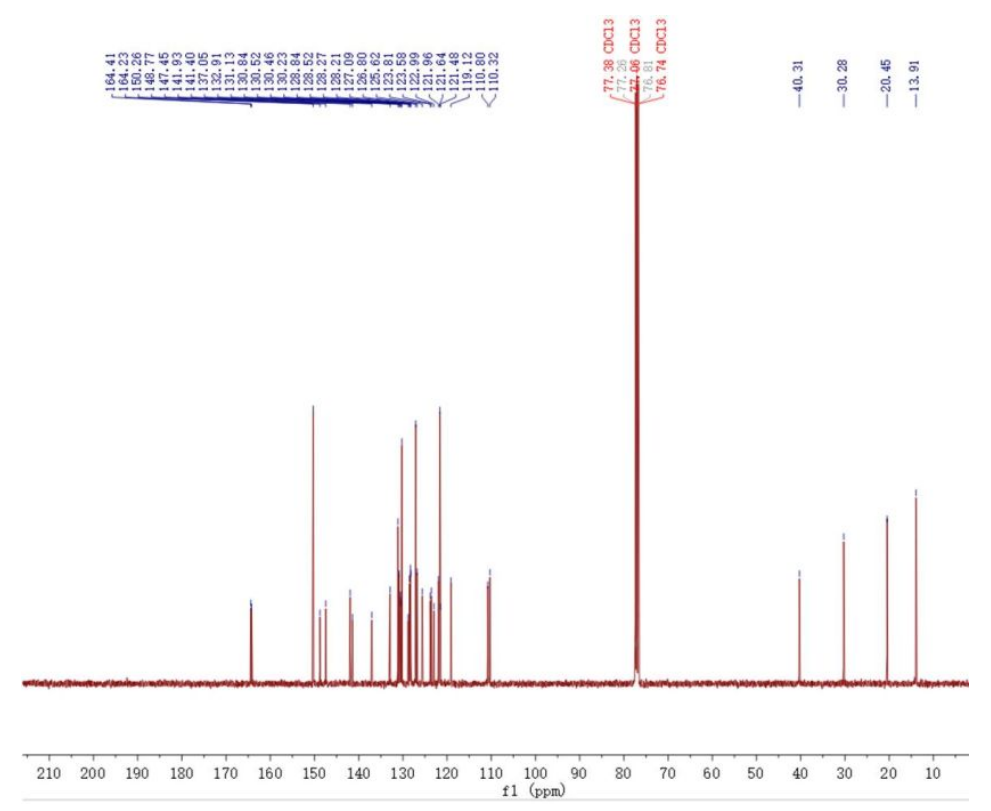

Figure S7. The 13C NMR spectrum of CzPy in CDCl3.

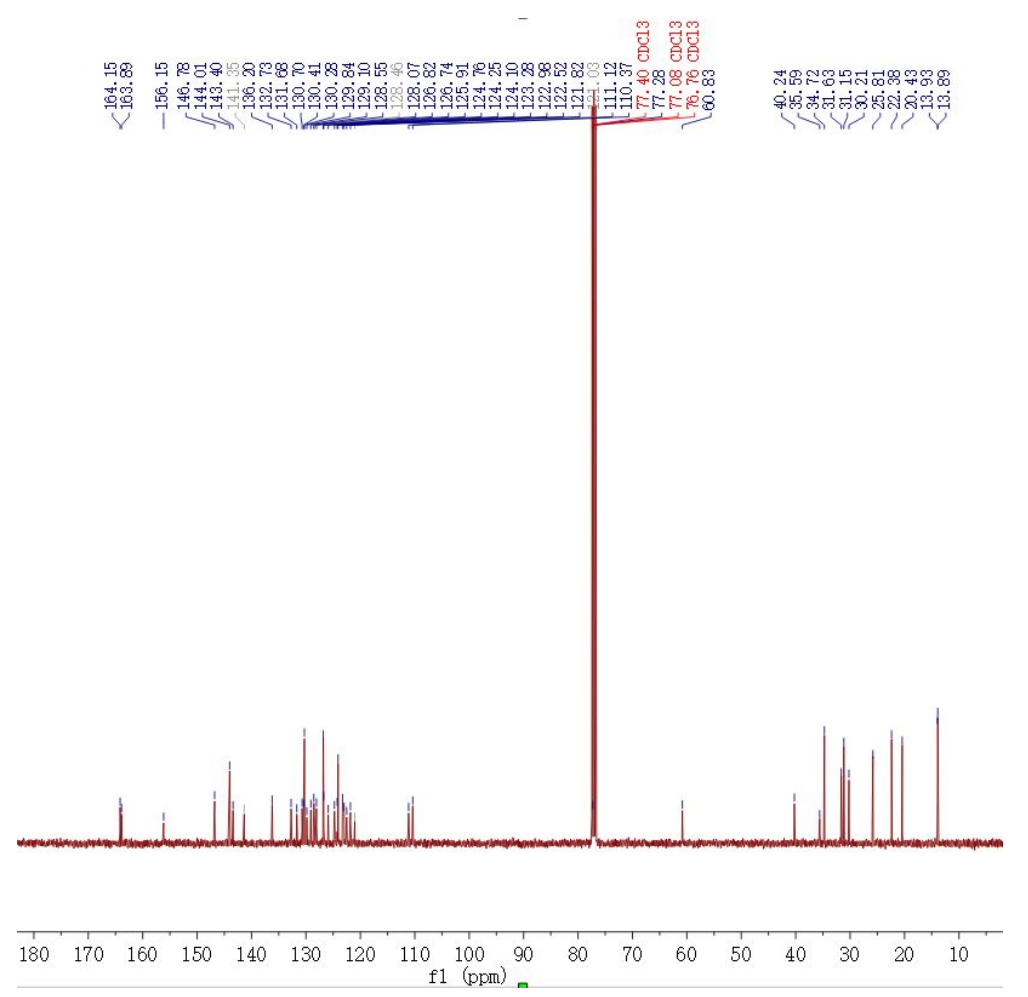

Figure S8. The 13C NMR spectrum of CzPyN in CDCl3. 


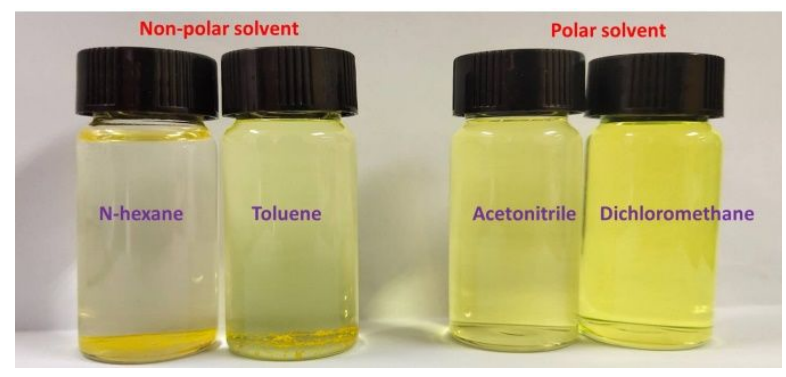

Figure S9. The optical picture of molecule $\mathbf{C z P y N}$ dissolved in different solvents.
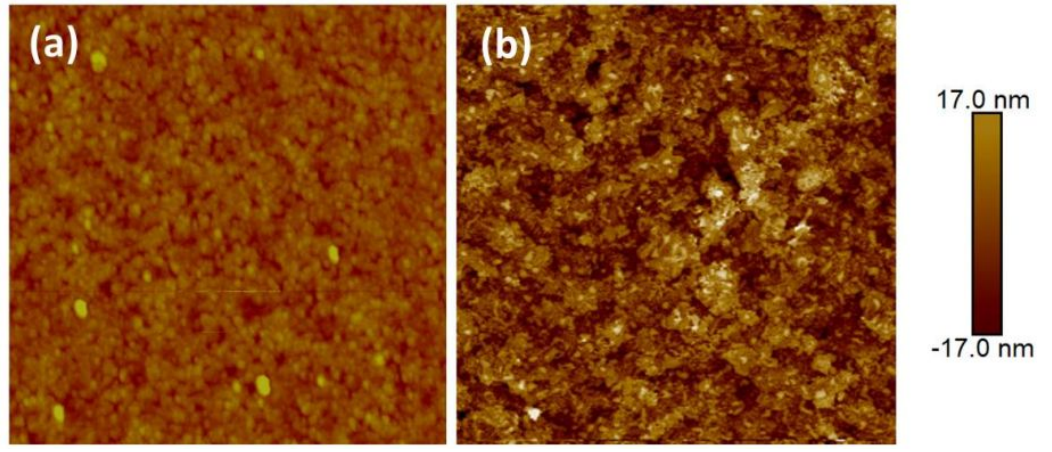

Figure S10. Representative AFM images $(5 \mu \mathrm{m} \times 5 \mu \mathrm{m})$ of the EPD films from different solvents: (a) acetonitrile; (b) dichloromethane.
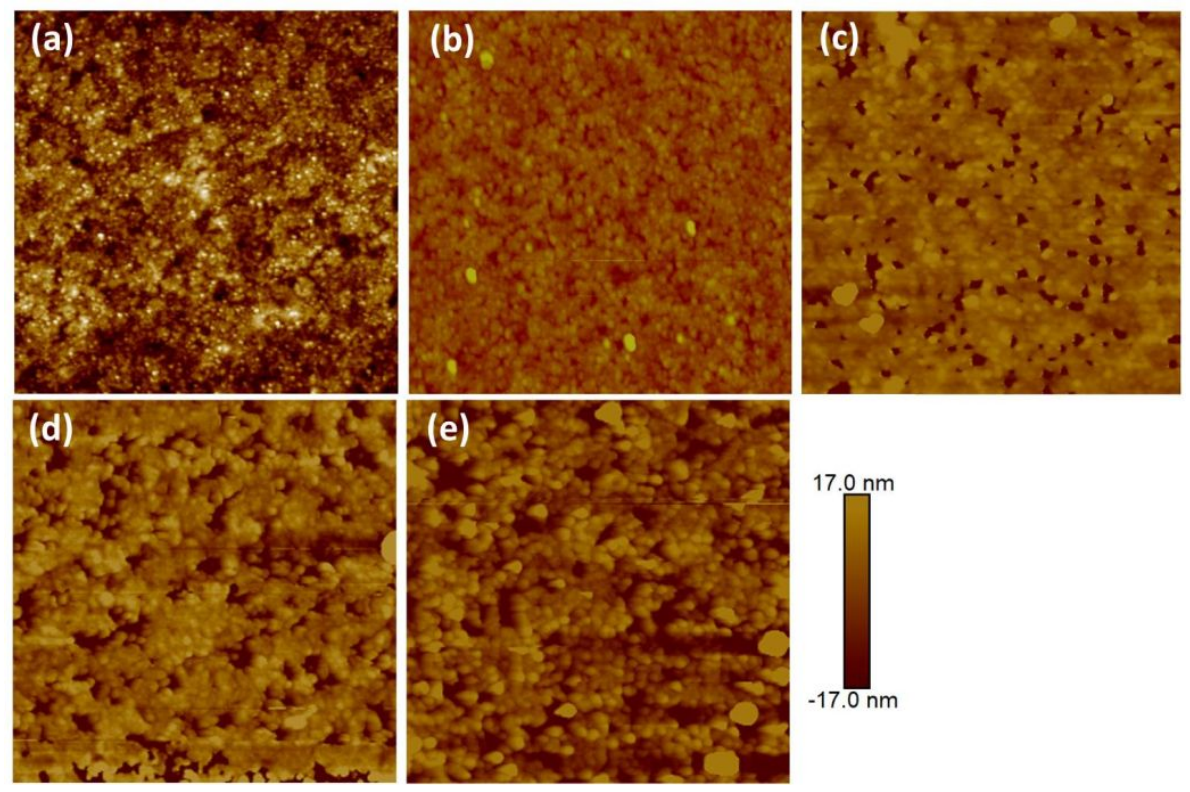

Figure S11. Representative AFM images $(5 \mu \mathrm{m} \times 5 \mu \mathrm{m})$ of a series of different EPD films with different concentration: (a) $0.1 \mathrm{mg} / \mathrm{ml}, \mathrm{Ra}=4.25 \mathrm{~nm}$; (b) $0.2 \mathrm{mg} / \mathrm{ml}, \mathrm{Ra}=$ $2.39 \mathrm{~nm}$; (c) $0.3 \mathrm{mg} / \mathrm{ml}, \mathrm{Ra}=5.12 \mathrm{~nm}$; (d) $0.4 \mathrm{mg} / \mathrm{ml}, \mathrm{Ra}=9.73 \mathrm{~nm}$; (e) $0.5 \mathrm{mg} / \mathrm{ml}$, $\mathrm{Ra}=10.9 \mathrm{~nm}$. 

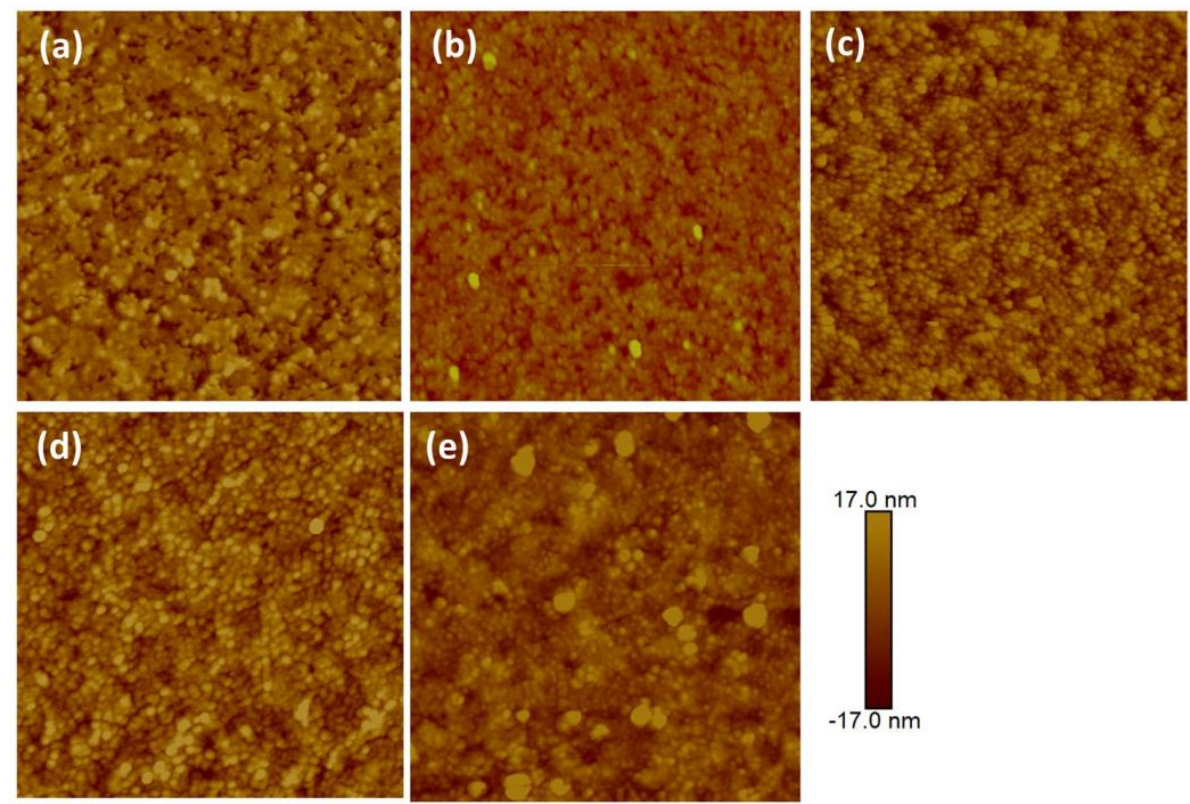

Figure S12. AFM images $(5 \mu \mathrm{m} \times 5 \mu \mathrm{m})$ of a series of different EPD films with different applied voltage: (a) $5 \mathrm{~V}, \mathrm{Ra}=5.25 \mathrm{~nm}$; (b) $8 \mathrm{~V}, \mathrm{Ra}=2.39 \mathrm{~nm}$; (c) $10 \mathrm{~V}$, $\mathrm{Ra}=5.18 \mathrm{~nm}$; (d) $13 \mathrm{~V}, \mathrm{Ra}=5.61 \mathrm{~nm}$; (d) $15 \mathrm{~V}, \mathrm{Ra}=6.64 \mathrm{~nm}$.

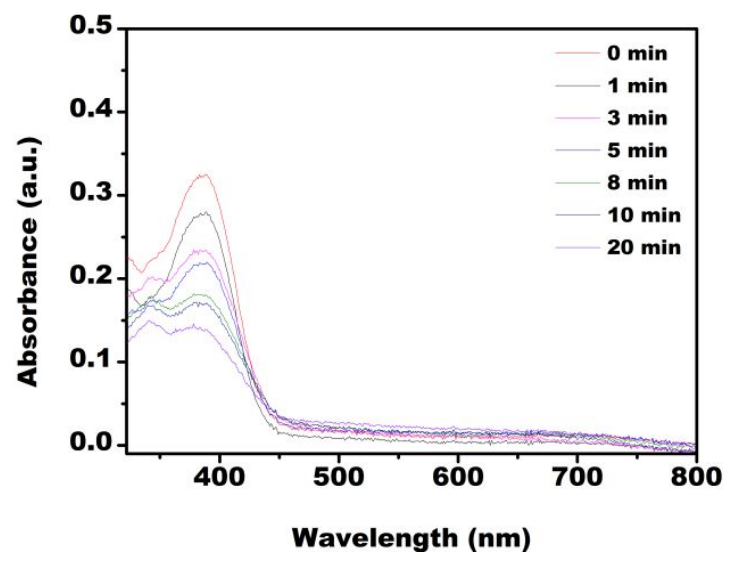

Figure S13. The UV-Vis absorption of the electrolyte solution, monitoring at different deposition times but the same voltage. 


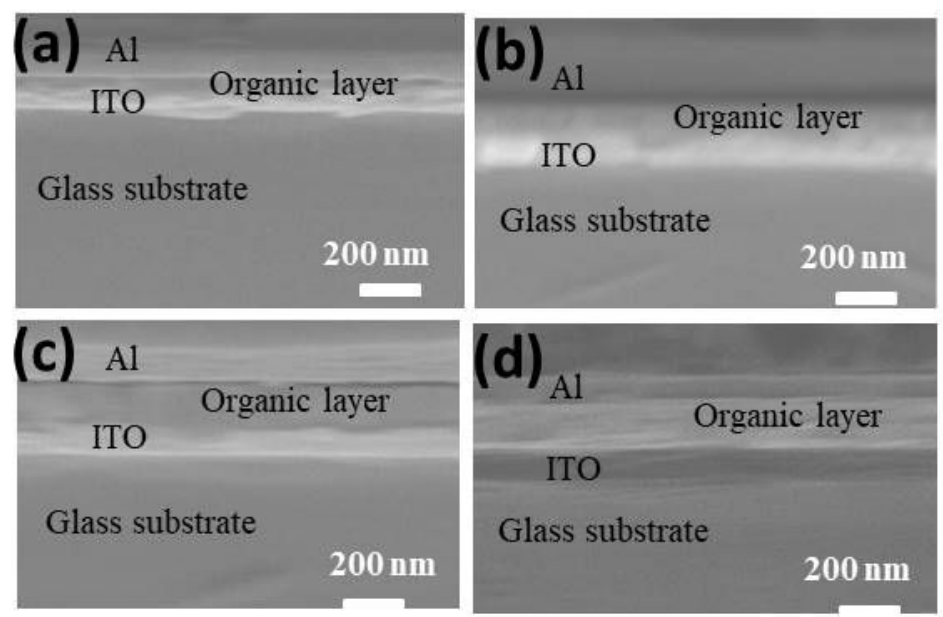

Figure S14. SEM cross sectional images of the thin films deposited under different times of EPD: (a) 3; (b) 5; (c) 8; (d) 10 minutes.
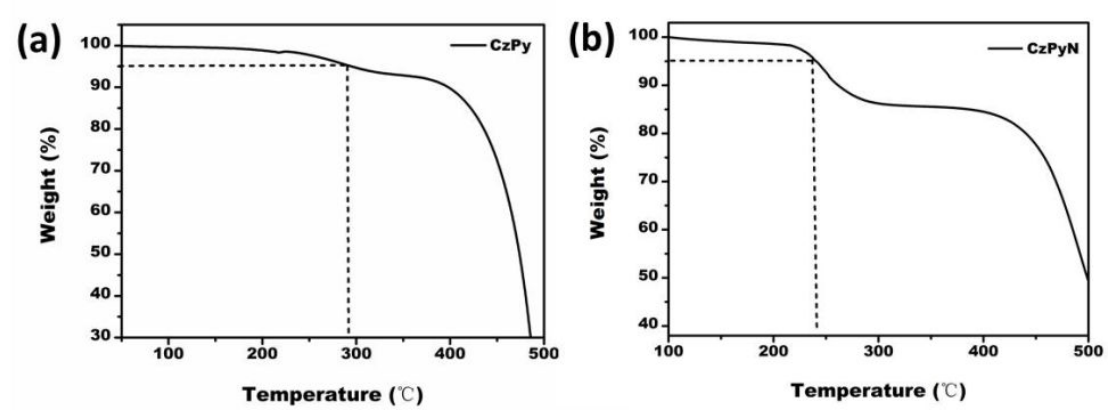

Figure S15. TGA curves of the small molecule (a) CzPy and (b) $\mathbf{C z P y N}$ measured at an air-flow rate of $10^{\circ} \mathrm{C} / \mathrm{min}$ under the $\mathrm{N}_{2}$ atmosphere.

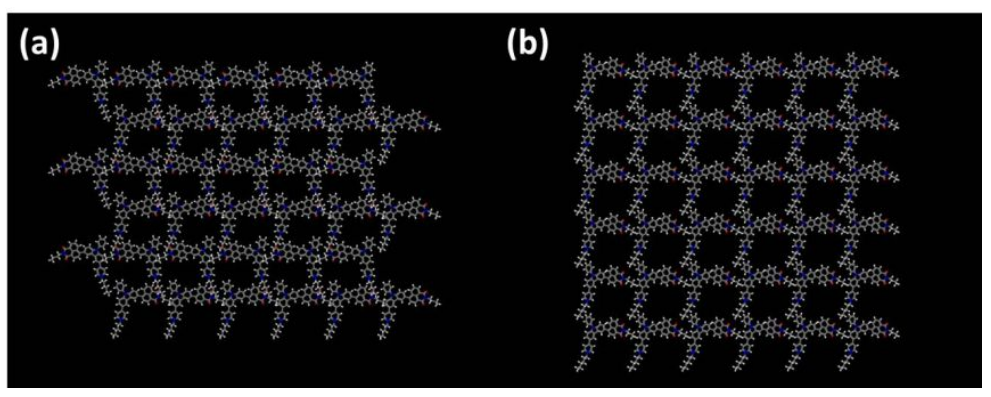

Figure S16. Theoretical simulation of internal stacking and arrangement of the molecules: (a) CzPyN-S; (b) CzPyN-E. 

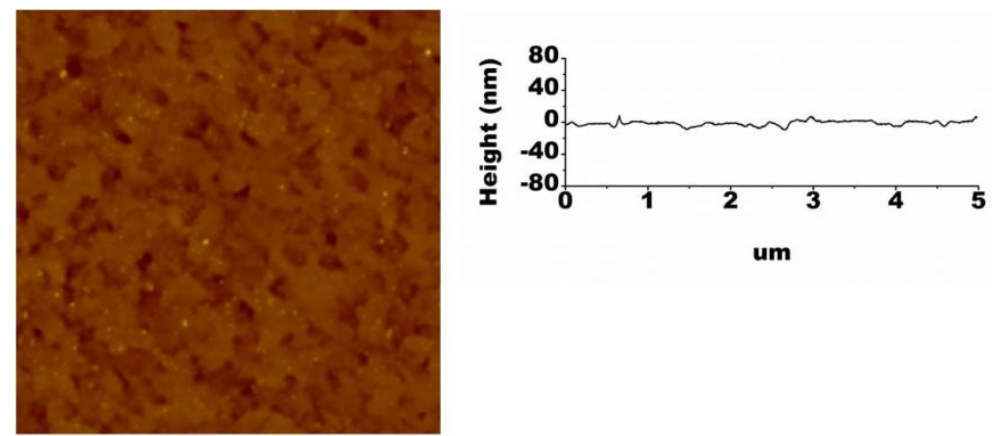

Figure S17. Morphology characterization of non-contact mode AFM topographic images $(5 \mu \mathrm{m} \times 5 \mu \mathrm{m})$ of $\mathbf{C z P y}-\mathbf{S}$.

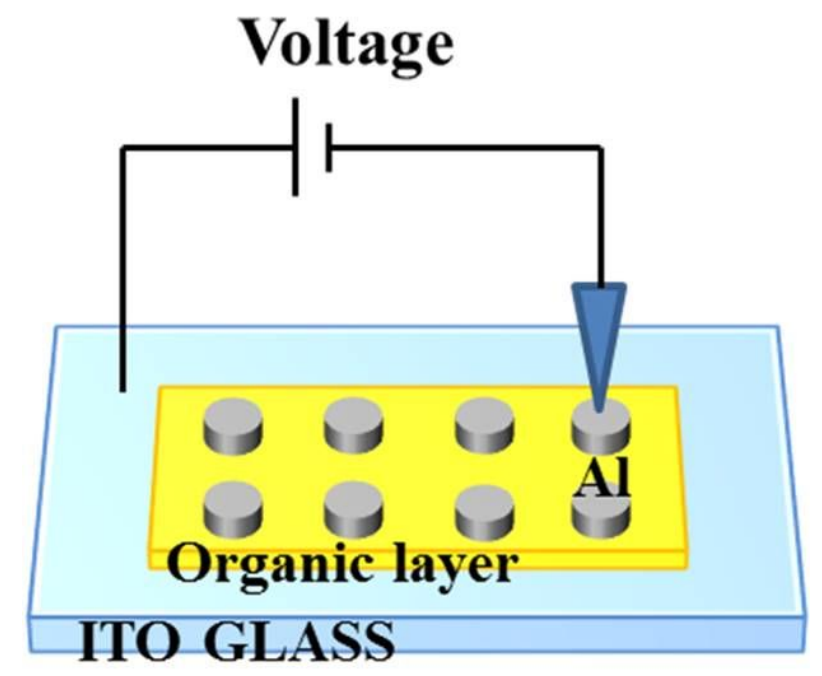

Figure S18. Schematic diagram of the sandwich-structured memory devices.

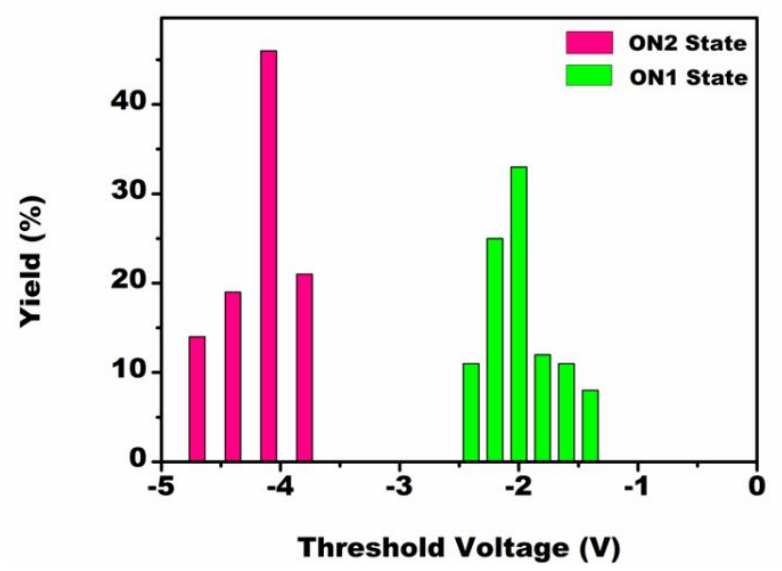

Figure S19. Threshold voltage distribution of the CzPyN-E based device shown as a column chart. 

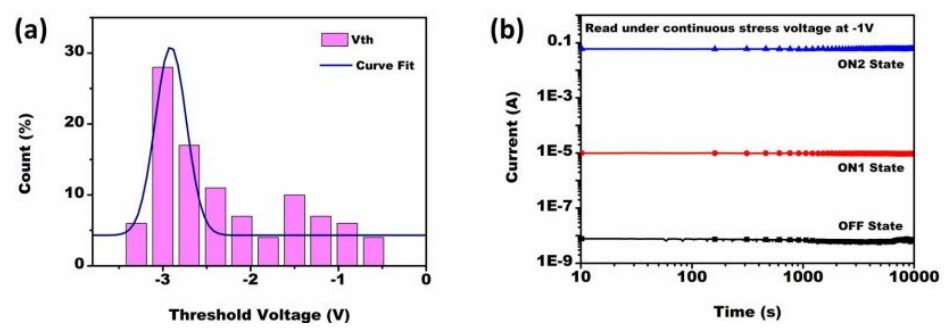

Figure S20. (a) The column-chart plot showed the detailed threshold voltage distributions of the $\mathbf{C z P y N}$-S-based device. (b) Stability test of the $\mathbf{C z P y N}-\mathbf{S}$ memory device.
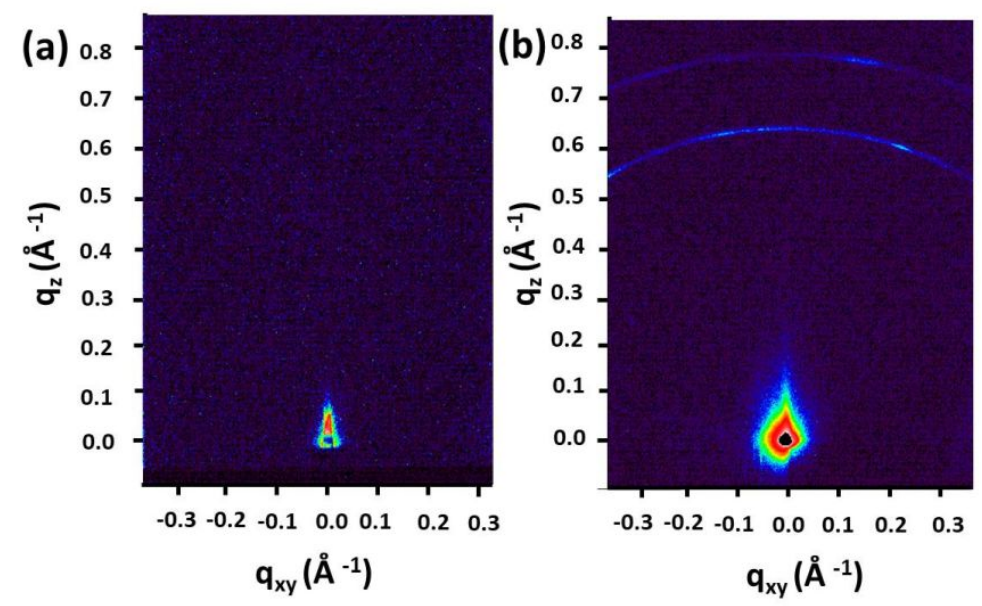

Figure S21. GISAXS diffractogram of (a) spin-coated film and (b) EPD film. GISAXS is with a very small incident angle of $0.2^{\circ}$ in point collimation mode.
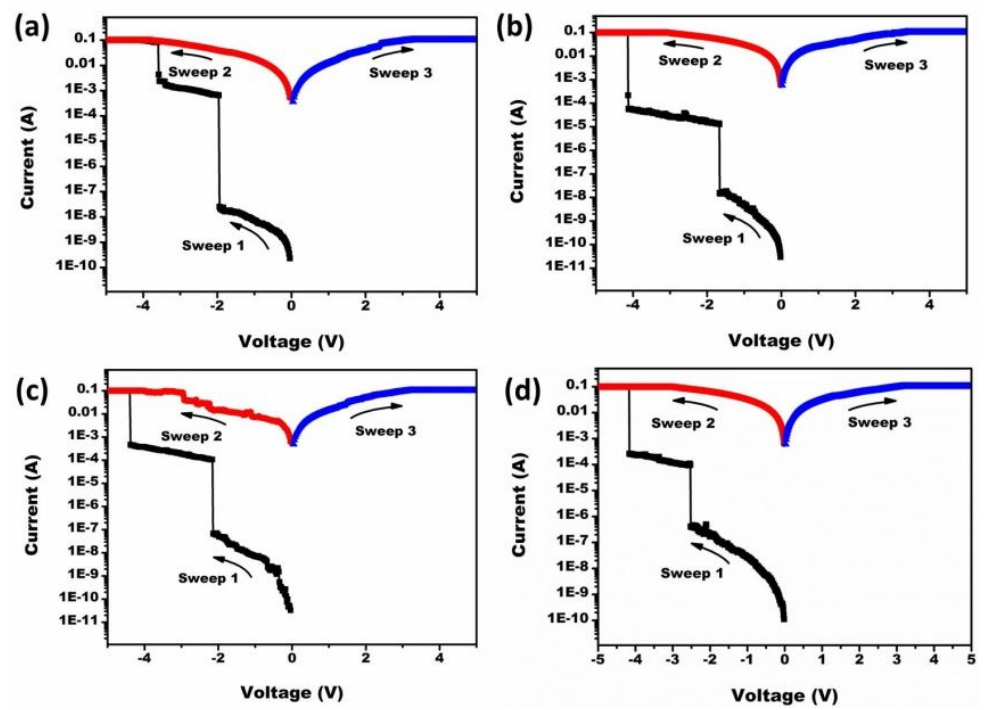
Figure S22. I-V characteristics of the CzPyN-E based different EPD films with different applied voltage: (a) $5 \mathrm{~V}$; (b) $8 \mathrm{~V}$; (c) $10 \mathrm{~V}$; (d) $13 \mathrm{~V}$.
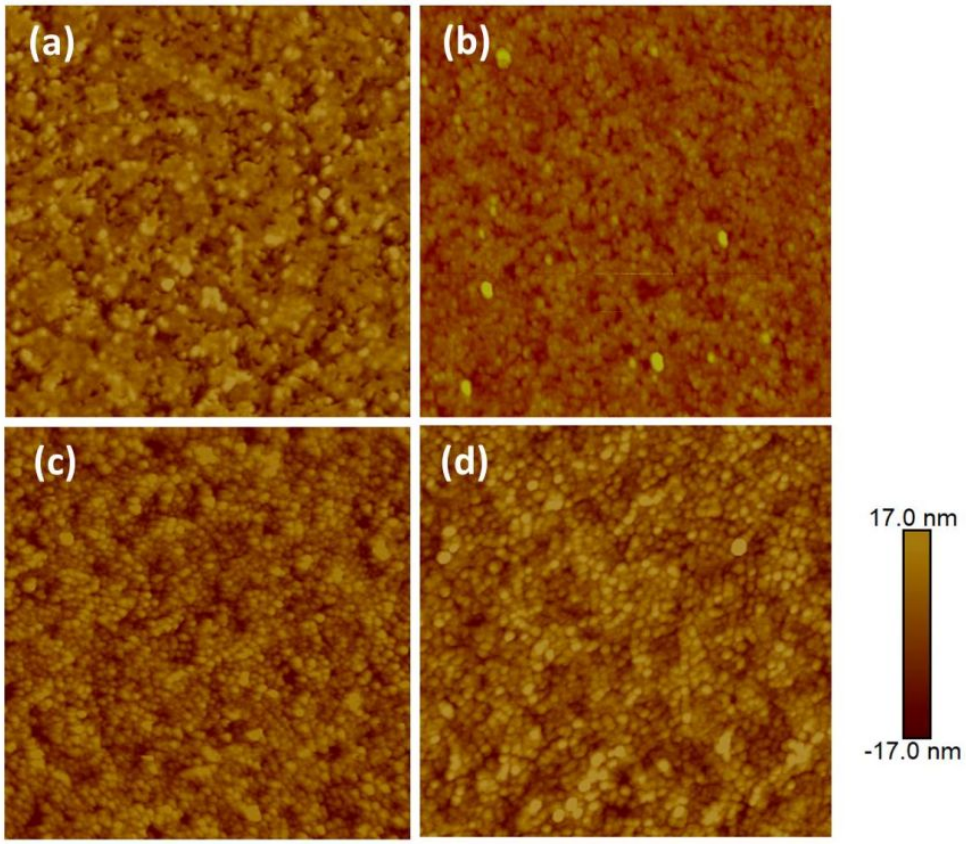

Figure S23. AFM images $(5 \mu \mathrm{m} \times 5 \mu \mathrm{m})$ of a series of different EPD films with different applied voltage: (a) $5 \mathrm{~V}, \mathrm{Ra}=5.25 \mathrm{~nm}$; (b) $8 \mathrm{~V}$, Ra $=2.39 \mathrm{~nm}$; (c) $10 \mathrm{~V}$, Ra $=5.18 \mathrm{~nm} ;(\mathrm{d}) 13 \mathrm{~V}, \mathrm{Ra}=5.61 \mathrm{~nm}$.
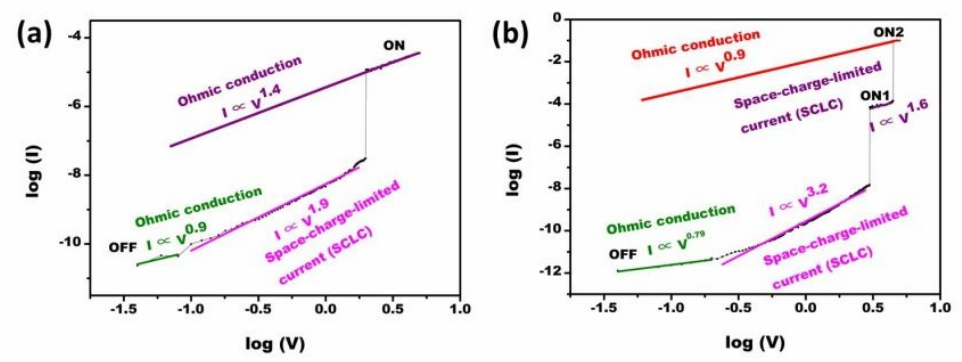

Figure S24. The $\log (\mathrm{I})-\log (\mathrm{V})$ curves of the devices: (a) ITO/CzPy-S/Al; (b) ITO/CzPyN-E/Al.

Table S1. Optical and electrochemical properties of $\mathbf{C z P y}$ and $\mathbf{C z P y N}$.

\begin{tabular}{|c|c|c|c|c|c|c|c|}
\hline Materials & $\lambda$ onset/nm & $E_{g} / e V$ & $\mathbf{E}_{\text {ox }} / \mathrm{eV}$ & HOMO/eV & LUMO/eV & $\Phi_{\text {Іто- }} \mathrm{E}_{\text {номо }}(\mathrm{eV})$ & $\mathbf{E}_{\text {LUMO }}-\Phi_{\mathrm{Al}}(\mathrm{eV})$ \\
\hline CzPy & 490 & 2.53 & 1.23 & -5.62 & -3.09 & 0.82 & 1.21 \\
\hline CzPyN & 513 & 2.41 & 1.21 & -5.60 & -3.19 & 0.80 & 1.11 \\
\hline
\end{tabular}

